\title{
Study on Factors Influencing Waste Disposal Cost and Optimize in FMCG Industry in Sri Lanka
}

\author{
D. I. Adipola ${ }^{\# 1}$, R. Mudunkotuwa ${ }^{* 2}$ \\ \#Department of Logistics and Transport, CINEC Campus \\ Millennium Drive, IT Park, Malabe, Sri Lanka. \\ ${ }^{1}$ dushanirantha@gmail.com \\ *Department of Logistics and Transport, CINEC Campus \\ Millennium Drive, IT Park, Malabe, Sri Lanka. \\ ${ }^{2}$ rashikadcinec.edu
}

\begin{abstract}
Waste is one of the greatest difficulties confronted by people in any country where waste contaminates indigenous habitat with devastating results if the authorities fail to take care accurately. In any case, it appears to be practically unavoidable that our general public, manufactures, industrial businesses etc produces waste whereas only can be minimized hence the point of this rationale thesis has been to explore how to recover the material assets by rethinking waste as an asset.

The study primarily focuses on two stakeholders, mainly FMCG companies in Sri Lanka who produces numerous waste per month and secondly the study focuses on professional recyclers who have ability to recycle under proper long-term agreements with unwavering trust.
\end{abstract}

This paper investigates a way of sustainably disposing product wastes of FMCG companies and also the determinants of waste disposal cost and ways of optimizing in fast moving goods industry in Sri Lanka. Thus, two questionnaires were distributed focusing on FMCG players and professional recyclers within Sri Lanka to measure determinants of waste disposal cost as well as to identify a strategy to aid generating profits instead of previously used cost generative process of direct disposing the FMCG wastage. Thus, factor analysis was conducted using two hundred and ten responses and the analysis extracts seven major factors as determinants to the waste disposal cost. This study concluded a successful waste disposal strategy as sorting and recycling where can change the current game play of the FMCG companies to a new direction.

Keywords - Waste management, Fast Moving Goods Industry, Recycler

\section{INTRODUCTION}

Throughout the history of mankind, the application of logistics and supply chain continue to emerge with the growing needs \& wants of users where Fast Moving Consumer Goods plays a vital role by satisfying those requirements in daily lives where traditional trade gives customer/consumer the same experience in buying as in old times while modern trade makes a new experience by giving consumers the opportunity to select their requirements themselves under one roof. However, both inter as well as intra traders compete to fulfil the social needs and wants of

Accordingly, different ways of product wastages defined according to Basel Convention of 1989 as "substance or objects, which are disposed of or are intended to be disposed of or are required to be disposed of by the provisions of national law" [1]. Hence, the rate of disposal has been on the rise, more and more damaged $\&$ expired goods are thrown away by wasting money and effort while making threats to the environment, society, individual and industries as well as devastating results attributable to increasing population and developing of industries. As there is a twofold scenario where people can't totally eliminate this issue it needs urgent solutions by changing the existing tracks on how companies work on this crucial area of managing waste [2].

Hence in a time period where product handling process is labour intensive in Sri Lanka and industries still can't afford capital intensive processes, this study covers the possibilities where can identify key areas of waste and optimize. Further, FMCG companies do not devote any time or effort to treat their waste [3] in Sri Lanka because they think that selling new products is more effective than spending money and resources on treating discarded equipment for make it usable again, especially in developing countries which do not have many legal frameworks for waste management [4].

Therefore, the overall significance of this study is that it will serve as a working document for policy makers to make regulations where currently existing regulations are based only on pesticide items disposal. This study is also an exemplarily way of turning garbage into wealth (money). So, it is hoped that this document shall be useful to other countries particularly in the developing sector which helps to balance economic, social and environmental objectives which are frequently in conflict in reverse logistics processes.

\section{METHODOLOGY}

\section{A. Identification of Variables}

The major objective of the study is to determine the factors affecting the waste disposal cost in the Fast-Moving Goods Industry in Sri Lanka and to identify and propose a more sustainable and cost-effective waste disposal strategy. Hence the author has identified waste disposal cost of Fast Moving Goods Industry as the dependent variable of this research and the determinants of waste disposal cost is considered as the independent variables which was summarized from the literatures respectively. Hence, these characteristics further concluded that this research takes the nature of a casual research.

\section{B. Questionnaire Design}

Initially a web based assessment questionnaire was prepared to overcome geographical barriers using Nominal, Likert and Interval scaling method to collect the primary 
data required for the study along with 21 factors as the factors affecting to waste disposal cost in FMCG industry in Sri Lanka. Besides, the questionnaire focused on the FMCG industry where FMCG waste is generated and consists of 3 segments for easy understanding of the questions.

\section{Sample Design}

In the view of all 65 companies including multinationals and locals who control the Sri Lankan FMCG business in small, medium and large scales which have licentiates to produce FMCG products, here the study mainly focuses on 45 companies including local \& multinationals all over in Sri Lanka and 5 questionnaires were distributed for each company for the purpose of collecting authorized data after the pilot survey confirmed the validation.

Altogether 210 primary responses were received out of the sample of 300 distributions by making available the questionnaire for a period of 50 days and secondary data was gathered from secondary sources such as scholarly articles, journals, reports and web pages based on waste management concepts in Sri Lanka as well as in international regimes.

However, varieties in the industry led researcher towards the stratified random sampling technique to design the sample \& hence all the distributed questionnaires categorized as $75 \%$ for multinationals \& $25 \%$ for local FMCG players as per the percentage in population since currently the market is dominating by multinationals from a percentage of $75 \%$ whilst local FMCG players only can afford for $25 \%$ market share in the competitive market.

Hence, selected sampling approach can be statistically justified since the sample represented more than $50 \%$ of the population with consideration of $95 \%$ confidence level.

\section{Validity and Reliability}

Cronbach's Alpha is used in statistics to measure the internal consistency/ reliability which is most commonly used to verify the reliability of the scale in a multiple LikertScale questionnaire. Higher rate of Alpha coefficient measured the questionnaire as being more reliable to collect the primary data related to the survey.

Conventionally, it is recognized that Cronbach's alpha coefficient requires 0.70 or has to be elevated to be reliable. Following equation (1) is for calculating total Cronbach's Alpha coefficient. The reliability test using Cronbach's Alpha coefficient has been carried out in this paper to check the reliability of the pilot and main surveys.

$$
\alpha=\frac{N \cdot C}{V+(N-1) \cdot C} \ldots \ldots \ldots
$$

$\mathrm{N}=$ the number of items.

$\mathrm{C}=$ average covariance between item-pairs.

$\mathrm{V}=$ average variance.

\section{E. Statistical Methods of Data Analysis}

Data collected through the questionnaire survey were fed into SPSS 16.0 (a statistical software tool) in order to generate a broad analysis of the study.

\section{F. Descriptive Analysis}

Descriptive analysis is broadly utilized as a part of the field of research, keeping in mind the end goal to summarize and show the information set close by. This specific factual train fundamentally compresses the elements in the sample in a quantifiable way, instead of summing it up to the population. Together with basic graphical presentations, descriptive measurements give a quantitative depiction of the example which is particularly helpful in distinguishing test attributes that are persuasive in making determinations of the sample. Insights, for example, frequency distribution, measures of central tendency \& measures of variability are analysed among others.

\section{G. Factor Analysis}

There are two types of factor analysis: exploratory factor analysis and confirmatory factor analysis. In this study exploratory factor analysis has been carried out which is a statistical method used to uncover the underlying structure of a comparatively large set of variables. The goal of exploratory analysis is to identify the underlying relationships between measured variables [5].

Descriptive insights, Bartlett's and Kaiser-Meyer-Olkin (KMO) test, Communalities, Total Variance, and Rotated Component Matrix is computed and analysed using SPSS 16.0 software. The Bartletts test compares the observed correlation matrix to the identity matrix. It checks whether there is a particular redundancy between the variables that can be summarized with a small number of factors. If the variables are perfectly correlated, only one factor is sufficient.

The Bartletts test checks whether the observed correlation matrix $R=$ (rij) ( $p \times x$ ) deviates significantly from the identity matrix.

H1a: Correlation matrix is an identity matrix. $\mathrm{H} 1 \mathrm{~b}$ : Correlation matrix is not an identity matrix.

Total variance is explained in the initial solution table. Eigen value is the total variance described by each factor. Eigen values that are less than one does not have enough total variance explained to represent a unique factor.

Eigen values which are less than 1 can be excluded from the variables. Thus, the overall KMO index is computed as follows.

$$
\frac{\sum_{i} \Sigma_{j} \neq\left(r^{2}\right)}{\sum_{i} \Sigma_{j} \neq\left(r^{2}\right)+\sum_{j} \neq\left(p^{2}\right)} \ldots \ldots .
$$

$p=$ Partial Correlation

$r=$ Correlation 


\section{H. Chi-square Test of Independence}

This particular test concludes whether there is a significant relationship between the two variables in the particular hypothesis or not. It is significant to state a significance level for this test beforehand which according to most researchers, is usually 0.5 . Same significance level has been used in this study when conducting the Chi-square test. Chi-square random variable $\left(\mathrm{X}^{2}\right)$ is defined by the equation below.

$$
X^{2}=\sum \quad\left(\frac{(O \gamma \varepsilon-E \gamma \varepsilon)^{2}}{E \gamma \varepsilon}\right) \ldots
$$

$\mathrm{X}^{2}=$ Chi-square random variable

Oү⿷ $=$ the observed frequency count at level $\gamma$ of Variable A and level $\mathcal{E}$ of Variable B

$\mathrm{E} \gamma \mathscr{E}=$ the expected frequency count at level $\gamma$ of Variable A and level $\mathscr{E}$ of Variable B.

Significant variables can be identified by analyzing the results of Chi-square test of independence. These significant ariables can be used to further analysis.

\section{DATA ANALYSIS}

\section{Descriptive Statistics}

TABLE I

COMPANY SIZE

\begin{tabular}{|c|c|c|c|c|}
\hline \multirow{2}{*}{ Valid } & Frequency & Percent & $\begin{array}{c}\text { Cumulative } \\
\text { Percent }\end{array}$ \\
\cline { 2 - 5 } & Small - Below 150 employees & 70 & 34.3 & 34.3 \\
\cline { 2 - 5 } & $\begin{array}{c}\text { Medium - 150 to 500 } \\
\text { employees }\end{array}$ & 84 & 41.2 & 75.5 \\
\cline { 2 - 5 } & Large - Above 500 employees & 50 & 24.5 & 100.0 \\
\cline { 2 - 5 } & Total & 204 & 100.0 & \\
\hline
\end{tabular}

According to Table I, 34.3\% of the respondents in the sample represent small scale FMCG companies which acounts for 70 responds and consequently $41.2 \%$. 24.5\% of the responds which account for 84 \& 50 respondents respectively represents Medium \& Large scale FMCG companies. Hence table demonstrates that the highest percentage of responds is in Medium scale FMCG companies where within the industry. And the all respondents positioned in all categories which will reduce the biasness. Hence the data set which is collected for the analysis will be very significant.

TABLE II

MONTHLY PRODUCT WASTAGE GENERATION

\begin{tabular}{|c|c|c|c|c|}
\hline \multirow{4}{*}{ Valid } & & Frequency & Percent & Cumulative Percent \\
\cline { 2 - 5 } & Below 4 ton & 58 & 28.4 & 28.6 \\
\cline { 2 - 5 } & Between 4-8 tons & 73 & 35.8 & 64.5 \\
\cline { 2 - 5 } & Between 8-14 tons & 45 & 22.1 & 86.7 \\
\cline { 2 - 5 } & Above 14 tons & 27 & 13.2 & 100.0 \\
\cline { 2 - 5 } & Total & 203 & 99.5 & \\
\hline
\end{tabular}

\begin{tabular}{|c|c|c|c|c|}
\hline Missing & System & 1 & .5 & \\
\hline \multicolumn{2}{|c|}{ Total } & 204 & 100.0 & \\
\hline
\end{tabular}

As per the Table II, the highest percentage level of generated waste size is occupied by 4-8tons category or $35.8 \%$ which accounts for 73 responds \& $28.4 \%, 22.1 \%$ \& $13.2 \%$ precentages of wasgate generation has occupied by below 4 ton, between $8-14$ ton \& above 14ton categories respectively \& accounts for $58,45 \& 27$ responses. Hence it concludes that most of the companies generate 4 to 8 tons of FMCG waste per month.

TABLE III

FREQUENCY OF WASTE CLEARANCE

\begin{tabular}{|c|c|c|c|c|}
\hline & & Frequency & Percent & Cumulative Percent \\
\hline \multirow[t]{5}{*}{ Valid } & Weekly & 24 & 10.7 & 17.4 \\
\hline & Once a month & 87 & 42.6 & 62.1 \\
\hline & Twice a month & 73 & 35.8 & 99.5 \\
\hline & Thrice a month & 11 & 6.5 & 100.0 \\
\hline & Total & 195 & 95.6 & \\
\hline Missing & System & 9 & 4.4 & \\
\hline \multicolumn{2}{|r|}{ Total } & 204 & 100.0 & \\
\hline
\end{tabular}

According to Table III, Waste clearance frequency of FMCG companies are high in once a month \& twice a month category which is shown as $42.6 \% \& 35.8 \%$ of the responses. In the perspective of recyclers Table II \& Table III, it concludes the business of recycling isn't unstable industry waste generation is huge as well as promising.

Figure 1 illustrates that the highest product wastage is generated in Expiration as well as in the production process \& smallest level of waste is generated at the transportation \& within warehouse hence in the FMCG Company's perspective; expiration is the critical scenario that need to be balanced somehow to manage waste generation.

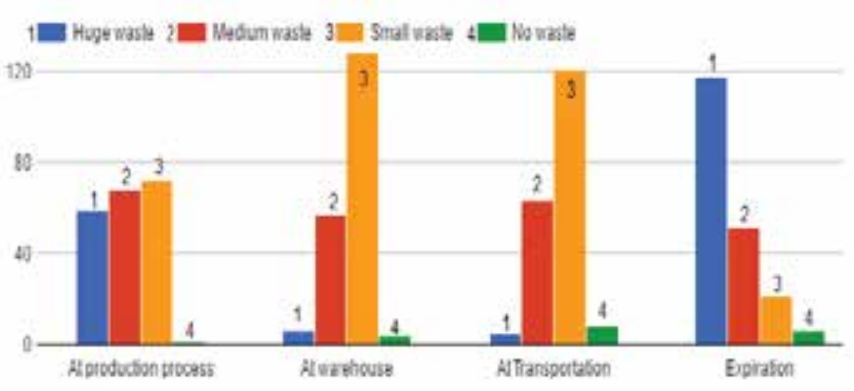

Fig.1 Waste generation scenarios 


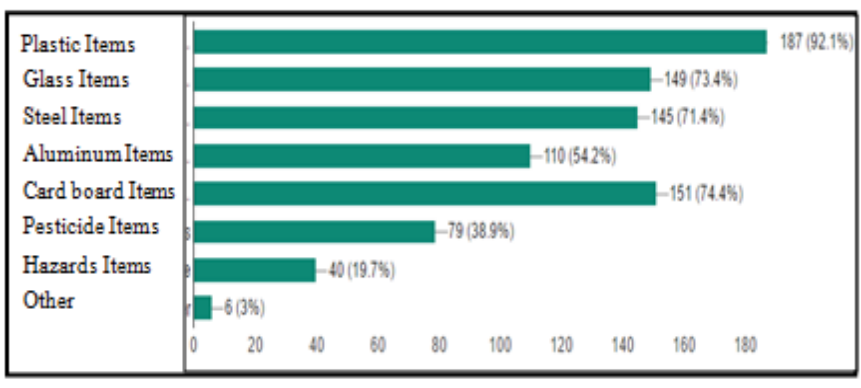

Fig.2 Types of FMCG waste

According to the figure 2 focused on parts \& components which an FMCG product is made of, most of the responses are weighted on plastic, glass, steel, aluminium \& cardboard items in a frequency of $187,149,145,110 \& 151$ respectively out of 205 total responses thus it could be concluded that almost $75 \%$ of FMCG companies use these types of parts \& components to develop finished products. Ultimately in waste disposal process also, the same percentages of components \& parts will be available resulting in recyclers collect enough levels of input to recycle.

However, components which can't be recycled or do not have legal authorization to recycle such as pesticide items \& hazardous waste should be disposed under incurring a cost whilst FMCG player has the option to choose whether all other normal components such as plastics, glass, steel etc. need to be disposed along with pesticides or sent to be recycled.

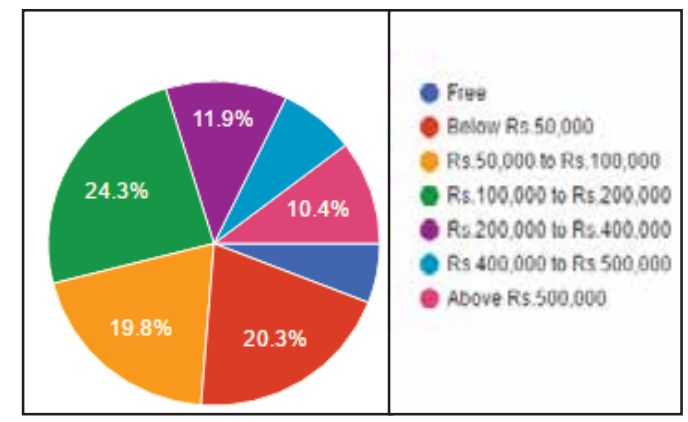

Fig.3 Cost of waste removal process

According to the Figure 3, 76.3\% percentage of FMCG companies have already paid up to Rs. 500,000 per month for their waste removal process which is a huge waste of money for unprofitable action. 10.4\% of companies have paid more than Rs. 500,000 per month which isn't acceptable by any FMCG player in Sri Lanka. Besides there are some methods such as recycling where revenue can be generated and can smooth line this process.

Furthermore, 2 important questions were asked in the warehouse focused questionnaire to identify the qualitative answer through the companies' view point. It is based on some options whereas if the municipality offered wastage pickup service to pick up unsorted waste from company's doorstep for a fee of Rs 20,000.00 per ton which is currently done by most of private disposers. The problem will be simple and will reduce the workload. However, confusion, reluctant to accept new innovations may reduce Sri Lankan business opportunities from achieving. Accordingly figure 4 illustrates acceptance levels are similarly distributed to all Yes, No, don't know categories in percentages of $38.6 \%$, $28.2 \% \& 33.2 \%$ respectively. Hence it is concluding that the same level of attitude will be there in the industry on accepting costs, sensitive on cost as well as having doubts on accepting the process which accounts for $33.3 \%$.

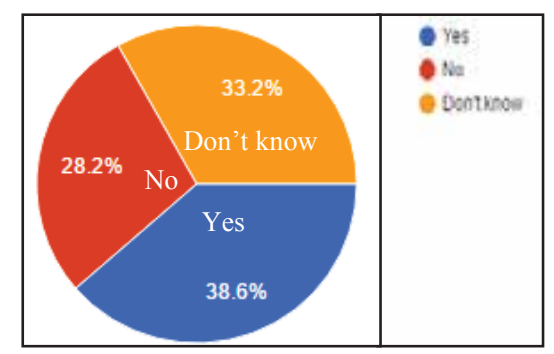

Fig.4 Acceptance level if the municipality offered services for waste collection

TABLE IV

PERCENTAGES OF RECYCLABLE PRODUCTS OF A COMPANY

\begin{tabular}{|c|c|c|c|c|}
\hline \multirow{7}{*}{ Valid } & & Frequency & Percent & $\begin{array}{c}\text { Cumulative } \\
\text { Percent }\end{array}$ \\
\cline { 2 - 5 } & $0 \%$ & 6 & 2.9 & 2.9 \\
\cline { 2 - 5 } & $10 \%$ & 1 & .5 & 3.4 \\
\cline { 2 - 5 } & $30 \%$ & 32 & 8.8 & 12.3 \\
\cline { 2 - 5 } & $50 \%$ & 68 & 33.3 & 27.9 \\
\cline { 2 - 5 } & $80 \%$ & 79 & 38.7 & 61.3 \\
\cline { 2 - 5 } & Total & 204 & 100.0 & 100.0 \\
\hline
\end{tabular}

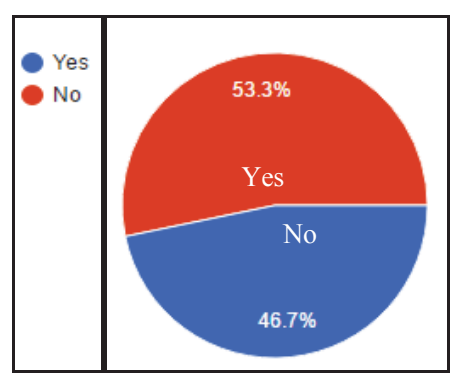

Fig.5 Does the company recycle its waste?

The above figure summarizes the percentage of companies who are already in recycling business and the rest. 53.3\% of the respondents denote that presently companies don't focus on recycling processes where as $46.7 \%$ of companies are engaged in recycling. Besides Table IV denotes that 79 respondents accounts for $38.7 \%$ and $68,32,18$ respondents account for $33.3 \%, 15.7 \%$ \& $8.8 \%$ respectively who products which can be recycled in its removal situation in a percentage of $80 \%, 50 \%, 30 \%$ and $10 \%$. Hence it is not a disability to send for recycling but there another reason which is analysed below in Figure 6. 


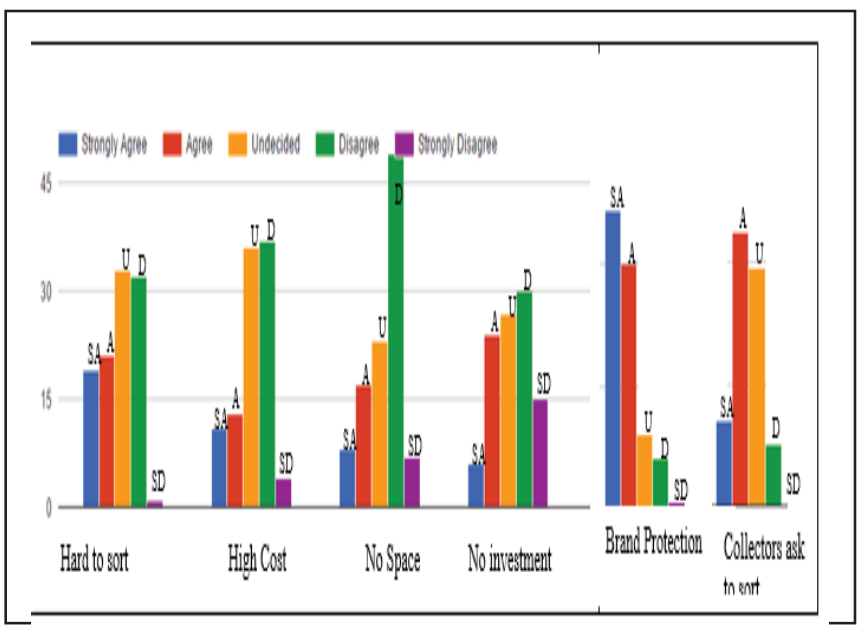

Fig 6: Reasons for not recycling

As illustrated in figure 6, most respondents noted that Hard to sort, High cost, no space \& No investment are not critical factors that drive companies away from recycling because reality is that sorting is not hard since one or two men can sort at the time of receiving the damaged/ expired products to warehouse collection centre without storing for post separation. Thus, most of respondents noted as neutral \& disagree on sorting point of view whereas some respondents accepted it is as a strongly agree scenario where they might be on situations in post separation.

Secondly, additional cost will not be generated if the process is going as stated in the above paragraph. Thirdly, there is no need of further investment \& space as sorting can be done in the same storage $\&$ only an initial small investment will be needed.

However, there are 2 major factors as per the analysis which diminishes the ability to recycle. Those are Brand protection policies \& Collectors ask to sort before collection. However, brand protection policies is a major issue in the industry for instance if a recycler tries to misuse the collected expired FMCG product by changing expiry dates \& sending to market again, it would be a reputational damage to product owner.

Nevertheless, some respondents suggested cutting the plastic bottles, breaking the glass bottles, chopping the steel $\&$ aluminium products may reduce the effect of this product misuse situations \& hence open up ways for greater recycling.

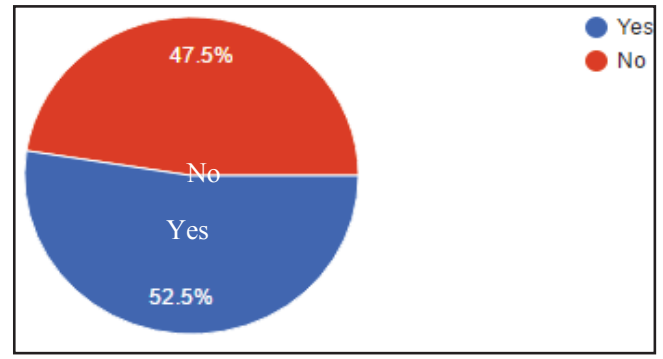

Fig.7 Does company sort product waste?

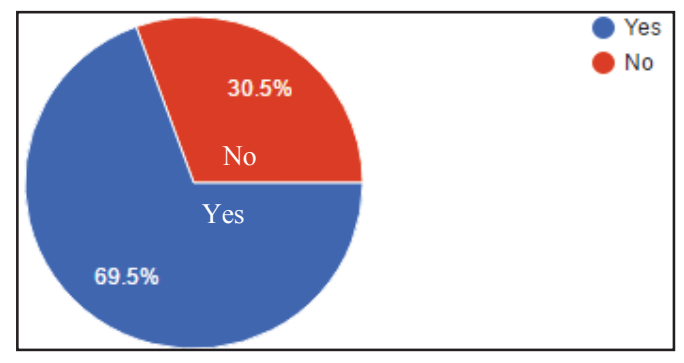

Fig. 8 Existence of professional waste collectors

Figure 7 illustrate that currently $52.5 \%$ of companies sort their product waste for recycling purposes whilst $47.5 \%$ of companies do not sort. Thus, it's a kind of 50-50 scenario where companies may face confusion whether to accept recycling or to continue the same procedure by just giving for disposal. Because a major barrier in developing countries is that not having professional product waste collectors who don't have proper contractual agreements on collection. However, Figure 8 illustrates that Existence of professional waste collectors in Sri Lanka is $69.5 \%$ while respondents who don't have awareness about professional collectors are $30.5 \%$. Hence it can be concluded that the existence of professional waste collectors is a reality in Sri Lanka besides it needs some kind of effort to identify them in areas nearby.

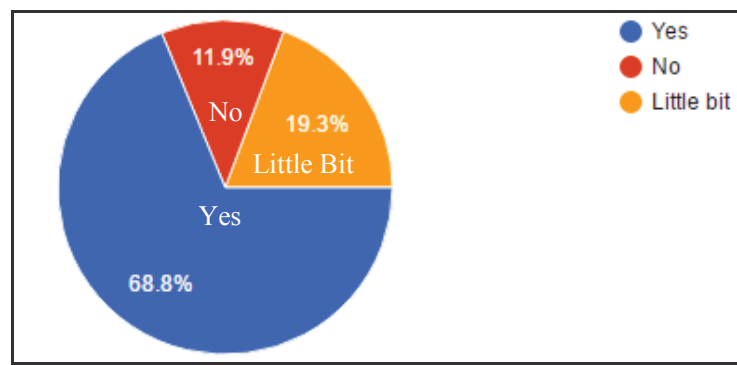

Fig.9 Awareness of FMCGs in other countries which make revenue out of recycling

However, figure 9 illustrate that most of the Sri Lankan FMCG companies are aware of FMCGs in other countries which make revenue out of recycling. But still people in Sri Lanka won't grab these opportunities.

In spite of that researcher tends to conclude that revenue can be generated if FMCG players focus on recycling rather than just disposing. Hence relevant hypothesis is,

\section{$\mathrm{H} 0=0$ : Revenue cannot be generated from recycling $\mathrm{H} 1$ = 1: Revenue can be generated from recycling}


TABLE V

CROSS TABULATION - (DO YOU RECYCLE YOUR WASTE? IF YES) * (CAN SAVE MONEY (ECONOMICAL)

\begin{tabular}{|c|c|c|c|c|c|c|}
\hline & Value & df & $\begin{array}{c}\text { Asymp. } \\
\text { Sig. (2- } \\
\text { sided) }\end{array}$ & $\begin{array}{c}\text { Exact } \\
\text { Sig. (2- } \\
\text { sided) }\end{array}$ & $\begin{array}{c}\text { Exact Sig. } \\
\text { (1-sided) }\end{array}$ & $\begin{array}{c}\text { Point } \\
\text { Probability }\end{array}$ \\
\hline $\begin{array}{c}\text { Pearson Chi- } \\
\text { Square }\end{array}$ & $13.067 \mathrm{a}$ & 3 & .004 & .008 & & \\
\hline $\begin{array}{c}\text { Likelihood } \\
\text { Ratio }\end{array}$ & 9.114 & 3 & .028 & .023 & & \\
\hline $\begin{array}{c}\text { Fisher's Exact } \\
\text { Test }\end{array}$ & 9.567 & & & .012 & & .066 \\
\hline $\begin{array}{c}\text { Linear-by- } \\
\text { Linear } \\
\text { Association }\end{array}$ & $2.040 \mathrm{~b}$ & 1 & .153 & .220 & .122 & \\
\hline $\begin{array}{c}\text { N of Valid } \\
\text { Cases }\end{array}$ & 100 & & & & & \\
\hline
\end{tabular}

a. 4 cells $(50.0 \%)$ have expected count less than 5 . The minimum expected count is . 11 .

b. The standardized statistic is 1.428 .

Table $\mathrm{V}$ is a cross tabulation between 'Do you recycle' \& 'Revenue can be generated with a chi-square of 0.004 $(0.05>0.004)$ which concludes that the relationship is very significant due to rejecting the null hypothesis. Therefore, the effort of this overall analysis results in a success which can be contributed to the FMCG industry as well to the recycling industry. Thus, this study concludes that revenue can be generated from recycling as it is an economy generative opportunity [26].

\section{J. Applicability of the Factor Analysis}

TABLE VI

\begin{tabular}{|c|c|c|}
\hline \multicolumn{2}{|c|}{ RELIABILITY STATISTICS } \\
\hline Cronbach's Alpha & $\begin{array}{c}\text { Cronbach's Alpha Based on } \\
\text { Standardized Items }\end{array}$ & N of Items \\
\hline .860 & .860 & 21 \\
\hline
\end{tabular}

Cronbach's Alpha is a measurement to test the reliability of the data set collected for analysis where higher the test statistics, higher the data set acceptance will be. Accordingly test statistic is 0.860 which illustrates higher Cronbach's Alpha value and thus the reliability of the variables is in the best level and data set can be acknowledged.

TABLE VII

KMO AND BARTLETT'S TEST

\begin{tabular}{|c|c|c|}
\hline \multicolumn{2}{|c|}{ Kaiser-Meyer-Olkin Measure of Sampling Adequacy. } & .745 \\
\hline Bartlett's Test of Sphericity & Approx. Chi-Square & $1.306 \mathrm{E} 3$ \\
\cline { 2 - 3 } & df & 210 \\
\cline { 2 - 3 } & Sig. & .000 \\
\hline
\end{tabular}

The Kaiser - Meyer - Olkin measure is a measure for degree of suitability of collected data for factor analysis. Accordingly, the test statistics of Table VII concluded that Kaiser-Mayer-Olkin (KMO) value as 0.745 which is greater than recommended value of 0.6 resulting in accepting the sample adequacy \& proceeding further with the factor analysis.

\section{K. Determine Number of Factors}

[6] \& [7] have noted the following regarding model development; initially the data should be analysed using a Principal Analysis to determine the number of factors. Hence Eigenvalue rule and Scree plot test were used to determine the appropriate number of components of the analysis.

TABLE VIII

ROTETED COMPONENT MATRIX

\begin{tabular}{|c|c|c|c|c|c|c|}
\hline \multirow{2}{*}{$\begin{array}{c}\text { Comp } \\
\text { onent }\end{array}$} & \multicolumn{3}{|c|}{ Initial Eigenvalues } & \multicolumn{3}{c|}{$\begin{array}{c}\text { Extraction Sums of Squared } \\
\text { Loadings }\end{array}$} \\
\cline { 2 - 7 } & Total & $\begin{array}{c}\text { Vof } \\
\text { Variance }\end{array}$ & $\begin{array}{c}\text { Cumulativ } \\
\mathrm{e} \%\end{array}$ & Total & Variance & $\begin{array}{c}\text { Cumulativ } \\
\mathrm{e} \%\end{array}$ \\
\hline 1 & 5.984 & 28.495 & 28.495 & 5.984 & 28.495 & 28.495 \\
\hline 2 & 3.010 & 14.333 & 42.828 & 3.010 & 14.333 & 42.828 \\
\hline 3 & 2.471 & 11.765 & 54.594 & 2.471 & 11.765 & 54.594 \\
\hline 4 & 1.290 & 6.141 & 60.735 & 1.290 & 6.141 & 60.735 \\
\hline 5 & 1.148 & 5.465 & 66.200 & 1.148 & 5.465 & 66.200 \\
\hline 6 & 1.048 & 4.989 & 71.189 & 1.048 & 4.989 & 71.189 \\
\hline 7 & .922 & 4.390 & 75.579 & .922 & 4.390 & 75.579 \\
\hline
\end{tabular}

Table VIII indicates the eigenvalues coupled with each linear factor before extraction, after extraction and after rotation where SPSS analysis has identified 21 factors within the data set. Moreover, 6 factors which total Initial Eigenvalues exceeds value 1 have been extracted initially in the extraction sums of squared loading section. However, scree plot denotes that the 7 th criterion also can be taken into consideration because its shape straightens not from criterion 6th onwards but from 7th onwards. Additionally, table VIII shows that its initial total eigen value is closer to 1 . Thus those 7 overall factors represent the overall 21 factors which the researcher had considered initially in the study because the ' $\%$ of variance' column of the extraction sums of squared loadings section summarizes degree of the total variability which can be accounted for. Accordingly, factor 1 , 2, 3, 4, 5, $6 \& 7$ of table VIII accounts for $28.495 \%$, $14.333 \%, 11.765 \%, 6.141 \%, 5.465 \%, 4.989 \%$ \& $4.390 \%$ respectively of the total variance whilst altogether these 7 gears explain the $75.579 \%$ variation of total variation. 


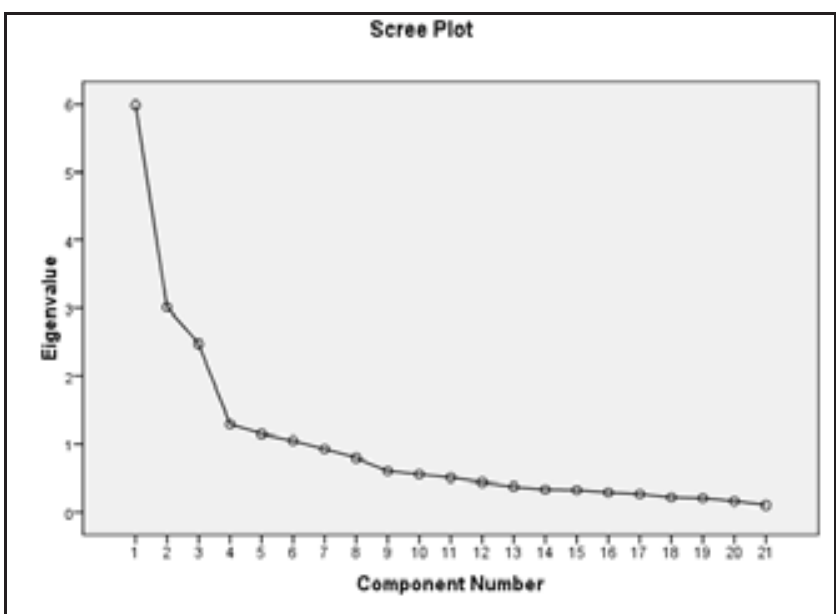

Fig.10 Scree Plot

According to Figure 10, there is a sharp turn (elbow) after the 7 th Eigen value. Hence scree plot further denotes that 7 of those factors explain most of the variability because the line starts to straighten after factor 7 . The rest of the variables clarify a little extent of the fluctuation and are likely to be insignificant. Thus, only six factors are retained for further analysis.

And those factors are identified as Regulatory Management \& prioritized Communication, Effective handling Process, Knowledge, Forecasting ability, Effective delivery Management, Production procedure management \& Quality of storage.

\section{Relationship between Extracted Factors and Demographics}

Relationship between Tons of wastage the company throw away monthly and the seven factors:

$\mathrm{H} 0$ : ith factor is independent from the Waste tonnage per month in the FMCG Company

$\mathrm{H} 1$ : ith factor is depending on the Waste tonnage per month in the FMCG Company

ith: (Regulatory management \& prioritized Communication, Effective handling process, Knowledge, Forecasting ability, Effective delivery management, Production procedure management, Quality of storage)

TABLE IX

CHI SQUARE TEST STATISTICS FOR 7 FACTORS VS. FMCG WASTAGE GENERATED MONTHLY

\begin{tabular}{|c|c|c|c|c|c|c|c|}
\hline & 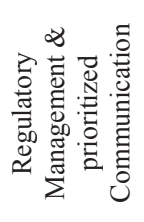 & 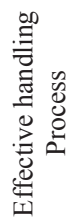 & 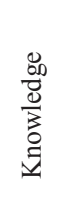 & 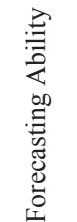 & 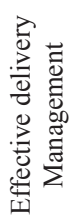 & 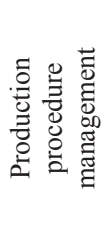 & 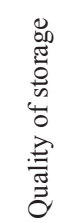 \\
\hline Chi-Square & 27.096 & 1.595 & $\begin{array}{c}2.74 \\
8\end{array}$ & $\begin{array}{c}16.18 \\
3\end{array}$ & 1.237 & .477 & 2.555 \\
\hline
\end{tabular}

\begin{tabular}{|c|c|c|c|c|c|c|c|}
\hline df & 3 & 3 & 3 & 3 & 3 & 3 & 3 \\
\hline $\begin{array}{c}\text { Asymp. } \\
\text { Sig. }\end{array}$ & .000 & .660 & .432 & .001 & .744 & .924 & .465 \\
\hline
\end{tabular}

a. Kruskal Wallis Test

b. Grouping Variable: Tons of wastage the company throws away

According to the statistics in above table, significance value of factor $1 \& 4$ (Regulatory management \& prioritized Communication, forecast ability) is lower than the recommended P-value of 0.5 thus leading to rejection of the null hypothesis and concludes that Regulatory management/ prioritized Communication \& Forecast ability are depending factors on Waste tonnage per month in the FMCG Company and have a better relationship too.

\section{Relationship between amounts paid for waste removal process and seven factors.}

H0: ith factor is independent from the Amount pay for waste removal process

H1: ith factor depends on the Amount paid for waste removal process

ith: (Regulatory management \& prioritized Communication, Effective handling process, Knowledge, Forecast ability, Effective delivery management, Production procedure management, Quality of storage)

TABLE X

CHI SQUARE TEST STATISTICS FOR 7 FACTORS VS. EXPENSES FOR WASTE REMOVAL

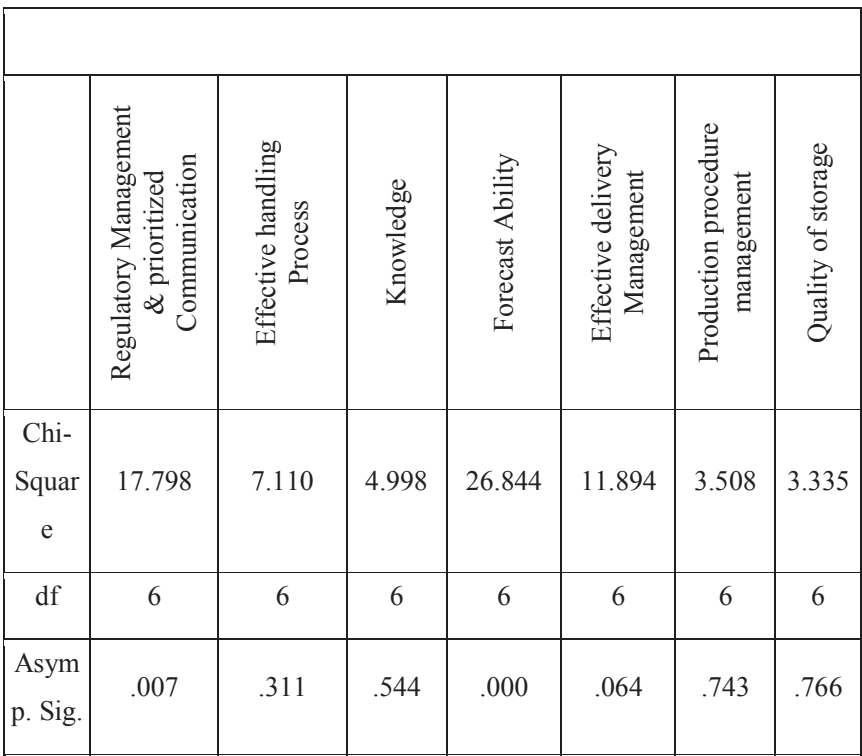

a. Kruskal Wallis Test

b. Grouping Variable: Amount pay for waste removal process monthly

According to statistics in above table, significance value of factor 1 \& 4 (Regulatory management \& prioritized Communication, forecast ability) lower than recommended P-value of 0.5 thus lead to reject null hypothesis \& concludes that Regulatory management/ prioritized Communication \& Forecast ability are depending factors on 
Amount pay for waste removal process and have a better relationship.

\section{CONCLUSION AND RECOMMENDATION}

As the initial step of study, researcher could be able to find some of the characteristics in sample population and as per the analysis it concludes that majority of the respondents were medium size companies who were actively engaged in waste collection \& accounts for $41.2 \%$ \& further concluded that amount of monthly wastage generated is between 4ton to 14 ton for $57.9 \%$ of the companies in Sri Lanka. And the frequency of waste clearance is twice or once a month for $78.4 \%$ which ensures recyclers input frequencies for recycling purposes where most of the recycler's mindsets are in a narrowed on the view of they could not be able to collect enough level of wastage to carry out the recycling business. Thus, here the study concludes that there is numerous level of FMCG wastage \& collection frequencies are wider to have a good recycling business.

In regarding the waste generation places, study concludes that highest product wastage generates in Expiration as well as in the production process \& smallest level of waste generates at the transportation \& within warehouse hence in the FMCG Company's perspective; expiration is the critical scenario that need to be balanced somehow to manage waste generation. And in the perspective of components which a FMCG product is made on, most of the responses are weighted on plastic, glass, steel, aluminium \& cardboard items thus conclude almost $75 \%$ of FMCG companies uses those type of parts \& components to develop finished products.

Currently, $76.3 \%$ percentages of FMCG companies have been already paying up to Rs. 500,000 per month for their waste removal process which is huge money waste for unprofitable action. Furthermore, two strong qualitative questions which based on warehouse sorting perspective concludes that, same percentages of attitudes will be there in the industry on accepting costs, sensitive on cost as well as some companies have doubts on accepting the recycling process.

In this sense, $53.3 \%$ respondents denote that presently companies don't focus on recycling processes but have $72 \%$ of recyclable items with them which can be recycled. Hence, reasons which most of respondents denoted are that Collectors ask to sort before collection \& Brand protection policies. However, brand protection policies are a major issue in the industry on reputational damage on actual product owner in situations where collectors misuse the collected expired FMCG product by changing expiry dates $\&$ send to market again [9]. And most of respondents noted that Harder to sort, High cost, no space \& No investment are not critical factors that drives away from recycling because reality is that sorting is not hard since one or two men can sort at the time of receiving the damaged/ expired products to warehouse collection centre without storing for post separation. Thus, most of respondents noted as neutral \& disagree on sorting point of view whereas some respondents accepted it is as a strongly agree scenario where they might be on situations in post separation.

However major barrier in developing countries are that not having professional product waste collectors which don't have proper contractual agreements on collection [10] whereas study concludes that existence of professional waste collectors in Sri Lanka is $69.5 \%$ while respondents who don't have awareness about professional collectors are $30.5 \%$. Hence it can be concluding that existence of professional waste collectors is a reality in Sri Lanka besides it needs some kind of effort to identify them in nearby.

Hence the fact is that businessmen reluctant to enter into this recycling area not due to workload, but of course FMCG don't know about the opportunity available in the industry where recycling is an economical, environmentally friendly process \& preserves existing raw material resources too. Finally, cross tabulation on recycling contribution vs economy generation concludes that Revenue can be generated from recycling as an economy generation process to the FMCG Company.

Moreover, though recycling is a strategy to reduce cost of waste disposal, priority of waste reduction by identifying factors of waste generation may also very important to cure the root of the problem. Hence in order to identify the factors of waste disposal cost, the structured questionnaire was constructed with 21 latent variables. Because of the large number of variables available in the research, factor analysis was carried out to reduce the number of variables \& accordingly factors were extracted to seven factors from the results of factor analysis. Rather with the assist of comprehensive literature evaluation concluded seven factors were named as "Regulatory Management \& prioritized Communication", "Effective handling Process", "Knowledge", "Forecast ability", "Effective delivery Management", "Production procedure management" \& "Quality of storage" for the ease of interpretation.

However, for recycling to achieve its intended purpose of contributing to waste management in Sri Lanka, the following recommendation may be helpful. As per the analysis carried out through the study it can be recommended to the FMCG companies that step on to recycling business where it can generate revenue as well as preserve environment far than now. In regarding the factors summarized in the analyze it is recommended to regulation makers to see on a big picture to identify where the regulations should be tightened as well as the places which regulations need to be loosened to make proper smooth pesticide \& hazardous disposal process in Sri Lanka.

And in the view point of expiration, most of the FMCG waste incurred through expiration where it happened due to lack of communication throughout the supply chain, but somehow in the modern trade the expiration can be managed by making value additions, banding the expiration nearby products when the products are on shelf using existing staff within the super markets thus it need proper coordination \& communication management to identify the needs relevant bands, stickers\& time limits of both FMCG player \& 
modern trade partners [11]. However, in traditional trade this expiration nearby product value addition can't be executed due to lack of proper coordination throughout Sri Lanka.

Further, forecasting of proper demand levels have to be properly executed \& thus production planners of the FMCG industry must directly adhere with that forecasted plan to reduce unwanted stocks in the market which will be ultimately be expired at the end \& thus increase waste removal cost too [12].

Despite of that, effective delivery, effective handling of product \& quality of storage are other facts which need to be focused in reducing the wastage amount in the industry for further extent.

Finally, despite of all above recommendations the major conclusion identified through this study is that the waste which incurred in the FMCG industry can be recycled \& it's an opportunity to transform current cost generating disposal process to revenue generating process. However most of the FMCG companies in Sri Lanka still confuse on this process. But here the study concludes \& recommended that any FMCG company can generate revenue through the recycling but it's up to the FMCG player to manage their sorting process accordingly by executing the sorting at the same time of receiving product waste to the warehouse collection point without stocking for post sorting because sorting is the biggest challenge which make barriers to enter into that recycling business.

\section{CONTRIBUTIONS AND IMPLICATIONS}

This study is very significant to the FMCG industry in a context of most of FMCG players incurred a huge level of money waste on the waste disposal process in each \& every month in Sri Lanka. Because, finding of this research become more \& more significant to make economical disposal process \& to contribute environment in more sustainable way.

In a framework of a better research, looking at waste from one perspective as a waste only is that an environmental disaster. Sometimes in the supplementary side it will have rich source of valuable resources that could be recovered profitably. Moreover, this dissertation investigates on how to dispose of unusable waste in more sustainable way which will helpful to existing FMCG players \& for new entrants to get viable opportunities swing in the industry. However, this must be controlled through the national legal \& environmental perspectives while delivering required obligations and responsibilities for the main actors.

\section{SCOPE \& LIMITATIONS}

The study is limited to the FMCG industry and as a major limitation it focuses only on industrial waste (FMCG product) disposal which was collected at the end of the month as expired, transport damages as well as handling damages etc \& not focuses on municipal waste \& e-waste of the companies. However, the study describes determinants to product waste disposal cost \& uses them to investigate a better \& sustainable way of cost effective waste disposal strategy.
Further the data was collected from fast moving consumer goods companies in Sri Lanka only, thus analyze the current situation within the country \& a comparison was done with the international countries on how they manage their waste management system through the reliable data sources obtained online.

\section{ACKNOWLEDGMENT}

At the completion of this dissertation it is a great pleasure to convey my gratitude for dedication and admiration made by many individuals in making this a success.

\section{REFERENCES}

[1] Basel Convention (1989). Convention on the Control of Transboundary Movements of Hazardous Wastes and their Disposal, December 23, 2016.

[2] Abel, O. A. (2009). An Analysis of Solid Waste generation in a Traditional African City: The Example of Ogbomoso, Nigeria. Environment and Urbanization, SAGE Journals, 19 (2):527-537.

[3] Blumenthal, K. (2011). "Generation and Treatment of Municipal Waste" Eurostat - Statistics in Focus Environment December 23, 2016.

[4] Countries. Environmental Systems Review No. 42/43. Bangkok, Thailand.

[5] Norris, G., Faiza, Q., Dennis, H,Duncan, C.(2012). Introduction to statistics with SPSS for social science. Harlow: Pearson.

[6] Miller et al (2002), Design and Analysis of Experiments, 5th edition.

[7] Pallant (2005), Analysis of interactions among the barriers of reverse logistics, Technological Forecasting and Social Change, Vol. 72, pp. 1011-29.

[8] Chirister.B, (2003). Economic efficiency in waste management in recycling. Department of business administration of social sciences division of economies.

[9] Ekberg, C. (2009). Waste Is What Is Left Behind When Imagination Fails. Sustainability: Web Journal from the Swedish Research Council Forum.http://sustainability.formas.se/en/Issues/Issue-4December-2009/Content/Focusarticles.

[10] El-Haggar, Salah M. (2007). Sustainable Industrial Design and Waste Management Cradleto- Cradle for Sustainable Development. Elsevier Ltd.

[11] Fuller Donlad.A, Allen, J. \& Glaser .M (1996). Materials recycling and reverse channel networks: The public policy challenge. Journal of Macro marketing, Vol.16, No.2, p.52-72.

[12] European Commission. (2011). "Roadmap to a Resource Efficient Europe". Brussels. 